\title{
Jerusalem artichoke and chicory inulin in bakery products affect faecal microbiota of healthy volunteers
}

\author{
Brigitta Kleessen $^{1}$, Sandra Schwarz ${ }^{1}$, Anke Boehm $^{2}$, H. Fuhrmann ${ }^{3}$, A. Richter ${ }^{4}$, T. Henle ${ }^{2}$ \\ and Monika Krueger ${ }^{1}$ \\ ${ }^{1}$ Institute of Bacteriology and Mycology, Veterinary Faculty, University of Leipzig, An den Tierkliniken 29, D-04103 \\ Leipzig, Germany \\ ${ }^{2}$ Institute of Food Chemistry, Technische Universität Dresden, Bergstrasse 66, D-01062 Dresden, Germany \\ ${ }^{3}$ Institute of Physiological Chemistry, Veterinary Faculty, University Leipzig, An den Tierkliniken 1, D-04103 Leipzig, Germany \\ ${ }^{4}$ Large Animal Clinic for Theriogenology and Ambulatory Services, Veterinary Faculty, University of Leipzig, An den Tierkliniken \\ 29, D-04103 Leipzig, Germany
}

(Received 16 October 2006 - Revised 21 February 2007 - Accepted 2 March 2007)

\begin{abstract}
A study was conducted to test the effects of Jerusalem artichoke inulin (JA) or chicory inulin $(\mathrm{CH})$ in snack bars on composition of faecal microbiota, concentration of faecal SCFA, bowel habit and gastrointestinal symptoms. Forty-five volunteers participated in a double-blind, randomized, placebo-controlled, parallel-group study. At the end of a $7 \mathrm{~d}$ run-in period, subjects were randomly assigned to three groups of fifteen subjects each, consuming either snack bars with $\mathrm{CH}$ or JA, or snack bars without fructans (placebo); for $7 \mathrm{~d}$ (adaptation period), they ingested one snack bar per day (7.7 g fructan/d) and continued for $14 \mathrm{~d}$ with two snack bars per day. The composition of the microbiota was monitored weekly. The consumption of $\mathrm{CH}$ or JA increased counts of bifidobacteria $\left(+1.2 \log _{10}\right.$ in $\left.21 \mathrm{~d}\right)$ and reduced Bacteroides/Prevotella in number and the Clostridium histolyticum/C. lituseburense group in frequency at the end of intervention $(P<0.05)$. No changes in concentration of faecal SCFA were observed. Consumption of snack bars resulted in a slight increase in stool frequency. Stool consistency was slightly affected in subjects consuming two snack bars containing $\mathrm{CH}$ or JA per day $(P<0.05)$. Consumption of $\mathrm{CH}$ or JA resulted in mild and sometimes moderate flatulence in a few subjects compared to placebo $(P<0 \cdot 05)$. No structural differences were detected between $\mathrm{CH}$ and JA before and after processing. In conclusion, adaptation on increased doses of $\mathrm{CH}$ or JA in bakery products stimulates the growth of bifidobacteria and may contribute to the suppression of potential pathogenic bacteria.
\end{abstract}

Bakery products: Inulin: Man: Faecal microflora: Processed foods

In modern Western societies the lifestyle is characterized by a highly caloric diet, rich in fat, refined carbohydrates and animal protein, combined with low physical activity, resulting in an overall energy imbalance. Facing the fact that such inappropriate dietary habits are contributing to health risks, including obesity, diabetes, CVD, arterial hypertension and cancer, optimal nutrition that focuses on optimizing the quality of daily diet by 'innovative foods' that favour the maintenance of health may help to decrease current and future health care costs.

Within the current discussion on functional foods, scientific research on the physiological effects of fructans is of importance for consumers when food manufacturers and retailers introduce new products with possible 'health benefits'. In the bakery industry, inulin or fructo-oligosaccharides from chicory (Cichorium intubus) roots or Jerusalem artichoke (Helianthus tuberosus) tubers are often used as fat replacers to improve the acceptability of low-fat products by the consumer.
Interest in these fructans for human nutrition also stems from their prebiotic properties. Prebiotics are defined as non-digestible food ingredients that beneficially affect the host by selectively stimulating the growth and/or activity of one or a limited number of potentially health-promoting bacteria in the colon such as bifidobacteria or lactobacilli ${ }^{1,2}$. Moreover, prebiotics are claimed to provide, by selective modification of the composition of the intestinal microflora, enhanced intestinal and systemic function, and reduction of risk of disease ${ }^{3-6}$.

Yet most of the research on prebiotic activity in man has been limited to inulin-type fructans of chicory roots $^{7-10}$, whereas inulin or fructo-oligosaccharides derived from other natural food plants, such as Jerusalem artichoke, have received little attention. Interest in their tubers for food purposes is derived from the special combinations of its prebiotic inulin and fructo-oligosaccharides, natural fructose, minerals, essential amino acids, vitamins and flavonoids.

\footnotetext{
Abbreviations: $\mathrm{CH}$, chicory inulin; dp, degree of polymerization; HPAEC-PAD, high-performance anion-exchange chromatography coupled with pulsed amperometric detection; JA, Jerusalem artichoke inulin.

* Corresponding author: Dr Brigitta Kleessen, fax +49341973 81 97, email b.kleessen@ gmx.de
} 
At the present stage of knowledge, different kinds of inulintype fructans are equally active as prebiotics in $\operatorname{man}^{7,10,11}$ but it cannot be excluded that these substrates incorporated into processed foods can influence the microflora in a different way.

Evidence exists that heat treatment of inulin-type fructans under conditions used for baking leads to changes of the fructan-structure and the formation of more low-molecular-weight degradation products ${ }^{12}$. The consequences of such heatinduced degradation reactions on the prebiotic properties of the fructans in vivo are rarely studied ${ }^{13}$.

Taking all the above aspects into account, we were interested in determining the effects of both chicory inulin $(\mathrm{CH})$ and Jerusalem artichoke inulin (JA) in snack bars on intestinal microbiota of healthy human subjects and to evaluate possible gastrointestinal side-effects associated with the consumption of these products. We compared the structure of inulin in raw materials and in processed snack bars, as possible changes during processing may occur which influence the properties of the fructans.

\section{Materials and methods}

\section{Subjects and study design}

A randomized, double-blind, placebo-controlled study with parallel groups that included forty-five healthy volunteers (students of the Veterinary Faculty, University of Leipzig, Germany) who maintained their usual lifestyle was carried out. All subjects (thirty-five women and ten men) aged 23.5 (SD 2.3) years completed the study. The BMI of the women was 22.4 (SD 2.7) $\mathrm{kg} / \mathrm{m}^{2}$ and of the men 23.4 (SD $1.4) \mathrm{kg} / \mathrm{m}^{2}$. Volunteers did not take any antibiotics or laxatives up to 6 months before the start of the study, nor did they take any during the study. Exclusion criteria were severe chronic disease, gastrointestinal disease, abdominal discomfort, constipation, severe food allergy, abnormal dietary habits (e.g. vegetarian, high fibres or soya diet, nutritional supplementation, excessive consumption of alcohol), pregnancy and non-compliance with stool sampling. The study was carried out with a 1-week run-in period followed by a 3 -week intervention period. During the run-in period, the volunteers were asked to consume their usual meals but excluding inulin-rich products like onions, leeks, bananas, artichokes, asparagus; inulin-fortified foods as well as fermented dairy products. All participants received a list of prohibited foods. At the end of the run-in period baseline levels of faecal bacterial populations were determined.

After the run-in period the participants were randomly assigned into three groups of fifteen subjects who consumed: (1) snack bars without supplementation of inulin (placebo), (2) snack bars with $\mathrm{CH}$ or (3) snack bars with JA. Subjects ingested one snack bar per day (between 07.00 and 08.00 hours) in the first week of the intervention period (adaptation phase to prevent adverse gastrointestinal side-effects), followed by consumption of two snack bars per day (between 07.00 and 08.00 hours and 19.00 and 20.00 hours) in the second and third week of the intervention period. The participants were instructed to maintain their dietary habits and physical activity pattern during the study. All participants were fully informed of the aims and course of the study and gave their written consent. The study protocol was approved by the Research Ethics Committee of the University of Leipzig, Germany.

Characterization of fructans before (raw material) and after bakery processing (snack bars)

The CH (Fibruline ${ }^{\circledR}$ Instant) was supplied by Cosucra, Brussels, Belgium.

Fibruline ${ }^{\circledR}$ Instant is a white powder obtained from chicory roots through conventional manufacturing techniques, including extraction with water, purification, isolation and drying. The product contains $88 \%$ inulin, maximum $10 \%$ free sugars (glucose, fructose and sucrose) and maximum $0.3 \%$ minerals. JA was obtained in the form of syrup from Liven $\mathrm{GmbH}$, Dabendorf, Germany. For production of the syrup, Jerusalem artichoke tubers were washed, hackled and squashed. The resulting slurry was filtered and the syrupy filtrate was evaporated to dryness. The finished product contains the following components: $55 \%$ inulin, $0.5 \%$ glucose, $2 \%$ fructose, $14 \%$ sucrose, $25 \%$ water, $3 \%$ minerals. The data were given by the manufacturer, except the inulin content, which was determined in our laboratory. For quantitative determination of the inulin content, a combination of two commercial test kits was used, which were supplied by r-biopharm (Darmstadt, Germany) and Megazyme (Bray, Ireland). The method is described in detail elsewhere ${ }^{12}$.

To map inulin profiles and to determine the degree of polymerization (dp), high-performance anion-exchange chromatography coupled with pulsed amperometric detection (HPAEC-PAD; Metrohm, Filderstadt, Germany) was used as described previously by Boehm et al. ${ }^{12}$. For qualitative and quantitative analysis, $0.5 \mathrm{~g}$ of each inulin was dissolved in $50 \mathrm{ml}$ bidistilled water and subjected to analysis as described earlier. Snack bars were extracted with hot bidistilled water $\left(80^{\circ} \mathrm{C}\right)$ for $15 \mathrm{~min}$, and inulin was quantified in the extract.

\section{Preparation of snack bars}

Snack bars were produced by Dr Quendt Backwaren GmbH (Dresden, Germany) for the present study. Three batches of snack bars were prepared (two batches containing approximately $7.7 \mathrm{~g}$ fructans/bar, differing in the supplemented kind of inulin-type fructans: $\mathrm{CH}$ or JA, and the placebo snack bars, which did not contain any supplemented fruc-

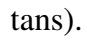

These bars (weight $36 \mathrm{~g}$ ) consisted of purely vegetable ingredients, which naturally did not contain any cholesterol or gluten. Snack bars without supplementation of inulin (placebo) contained a cereal mixture and a binder to approximately equal shares. The cereal composition contained ready-to-eat cereal pieces like rice crisps $(20 \%)$, roasted soyabean seeds $(12 \%)$, cornflakes $(12 \%)$ and buckwheat $(3 \%)$. The cereals were mixed with slightly heated binder consisting of several juice concentrates (apple, aronia, apricots, pineapple), dried fruits (cranberries, apricots, pineapple) and a thickening agent. The fluffy mass was rolled out evenly and dried at $135^{\circ} \mathrm{C}$ for $18 \mathrm{~min}$. After cooling, the dough was cut in bars of similar size. Snack bars with JA contained syrup of the tubers of Jerusalem artichoke in substitution to 
the equal amount of juice concentrates. Snack bars with $\mathrm{CH}$ consisted of Fibruline ${ }^{\circledR}$ Instant, which was also a component of the binder.

\section{Collection and processing of stool samples}

Fresh stool samples were collected at the end of the run-in period (on day 7) and weekly during the intervention period (days 14, 21 and 28). Volunteers were asked to bring the samples as soon as possible after defecation. Stool samples were processed within $2 \mathrm{~h}$ of collection. For whole-cell fluorescent in situ hybridization, $1 \mathrm{~g}$ faecal aliquots were fixed with paraformaldehyde as described previously ${ }^{14}$. For analysing SCFA, $0.2 \mathrm{~g}$ of specimen was prepared as described by Kruse et al. ${ }^{14}$.

Bacterial enumeration using fluorescent in situ hybridization combined with conventional microbiological culture techniques

Whole-cell fluorescent in situ hybridization was performed on silanized microscope slides ${ }^{15}$ with indocarbocyanin Cy3labelled 16S/23S rRNA-targeted oligonucleotide probes: (1) an equimolar mixture of five Bacteria-directed probes EUB 338 (S-D-Bact-0338-a-A-18), EUB 785 (S-D-Bact-0785-aA-19), EUB 927 (S-D-Bact-0927-a-A-17), EUB 1055 (S-DBact-1055-a-A-20), EUB 1088 (S-D-Bact-1088-a-A-20) ${ }^{16,17}$, referred to as EUB mix, to detect all bacteria; (2) Erec 482 (S-*-Erec-0482-a-A-19) specific for most of the clostridia and eubacteria belonging to the Clostridium coccoides/ Eubacterium rectale group ${ }^{18}$; (3) Bac 303 (S-*-Bacto-0303a-A-17) to detect the Bacteroides/Prevotella cluster ${ }^{19}$ combined with a set of two probes for species of the Bacteroides fragilis group Bfra 602 (S-*-0602-a-A-19) and the species Bacteroides distasonis Bdis 656 (S-*-Bdis-0656-a-A-18) ${ }^{18}$; (4) Fprau 645 (S-*-Fprau-0645-a-A-23) for the Faecalibacterium prausnitzii group ${ }^{20}$; (5) the bifidobacterial probe Bif 164 (S-G-Bif-0164-a-A-18) ${ }^{21}$; (6) Ato 291 (S-*-Ato-0291-aA-17) to detect species of the Atopobium cluster $^{22}$; (7) Chis150 (S-*-Chis-0150-a-A-23) to detect bacteria of the Clostridium histolyticum group; (8) Clit135 (S-*-Clit-0135a-A-19) to detect clostridia belonging to the Clostridium lituseburense group ${ }^{18}$. After hybridization bacterial cell enumeration was performed using an epifluorescence microscope (Axioskop, Carl Zeiss, Germany). The detection limit of the method was determined to be $\log _{10} 5 / \mathrm{g}$ stool. Therefore, the cultural approach was used for the detection of some less abundant microbial groups/species in human faeces which might be affected by fructan-type inulin. Enterobacteriaceae, lactobacilli, enterococci and Clostridium perfringens and yeasts were determined using selective media and incubation conditions that have been described previously ${ }^{23,24}$.

\section{SCFA}

SCFA were extracted as described previously by Kruse et al. ${ }^{14}$. Samples of $1 \mu \mathrm{l}$ were injected into a gas chromatograph (GC 3900; Varian Deutschland GmbH, Germany) equipped with a flame-ionization detector and a capillary column. Helium was used as carrier gas at a column flow rate of $1.5 \mathrm{ml} / \mathrm{min}$ with a split ratio of $1: 10$. The temperature of both detector and injector was $230^{\circ} \mathrm{C}$. The concentrations of SCFA were calculated based on peak areas according to the internal standard method using isocapronic acid as an internal standard.

\section{Assessment of bowel habit and gastrointestinal symptoms}

During the whole study period, volunteers kept a daily chart and recorded subjective intestinal characteristics, stool frequency and stool consistency, and the time of snack bar consumption. Gastrointestinal complaints concerning repeated flatulence, abdominal bloating, abdominal pain, bowel rumbling as well as bowel cramps could be selected as being absent (0), mild (1), moderate (2) or severe (3). Stool consistency was also scored from 1 (hard) to 4 (watery).

\section{Statistical analysis}

Statistical analyses were conducted with the Statistical Package for Social Science, version 11.5 (SPSS Inc., Chicago, IL, USA). Normal distribution of analytical variables was checked with the Shapiro-Wilk test. The general linear model repeated measure procedure was used to test between treatment groups and within group differences in the repeated continuous variables. If there were significant overall effects, ANOVA with the Bonferroni test was used for between treatment group analyses and the paired samples $t$ test for within group analysis. The Pearson Chi-square test was used to assess the significance of differences between the numbers (percentage) of subjects harbouring specific bacteria. The occurrence and the intensity of gastrointestinal symptoms were scored on the basis of the $7 \mathrm{~d}$ observations both in the run-in period and weekly during the intervention period. Groups were compared statistically using the non-parametric Kruskal-Wallis and Mann-Whitney $U$ test. Time comparison was done with the Friedman and Wilcoxon signed-rank test ${ }^{25}$. Before statistical analysis of the bacteriological results, the cell counts were transformed to $\log _{10}$ numbers. Differences were considered to be significant at $P<0 \cdot 05$.

\section{Results}

Fructans before and after processing of snack bars

HPAEC-PAD patterns of $\mathrm{CH}$ and JA are shown in Fig. 1. For semi-quantitative characterization, the inulin profile was separated into defined dp ranges and the relative peak area was calculated after integration $^{12}$. With dp values mainly between 5 and $12, \mathrm{CH}$ and JA belong to the short-chain inulin-type fructans. Inulin from chicory comprises approximately $46 \%$ fructose chains with dp 5-12, $24 \%$ fructo-oligosaccharides with dp below 5 , and the residual fructose units show a dp higher than 12 . Only $2 \%$ of the inulin is found in the higher molecular weight fraction above a dp of 30 . Inulin from syrup of Jerusalem artichoke contains approximately $40 \%$ fructose chains with dp below $5,49 \%$ with dp between 5 and 12 and only $11 \%$ chains with dp above 12 . The inulin content was analysed in both inulin samples based on fructose quantification after enzymatic hydrolysis. The inulin content of JA is lower $(54.8 \mathrm{~g} / 100 \mathrm{~g})$ than that of $\mathrm{CH}(88.0 \mathrm{~g} / 100 \mathrm{~g})$. The contents of inulin of the produced snack bars, also 
(a)

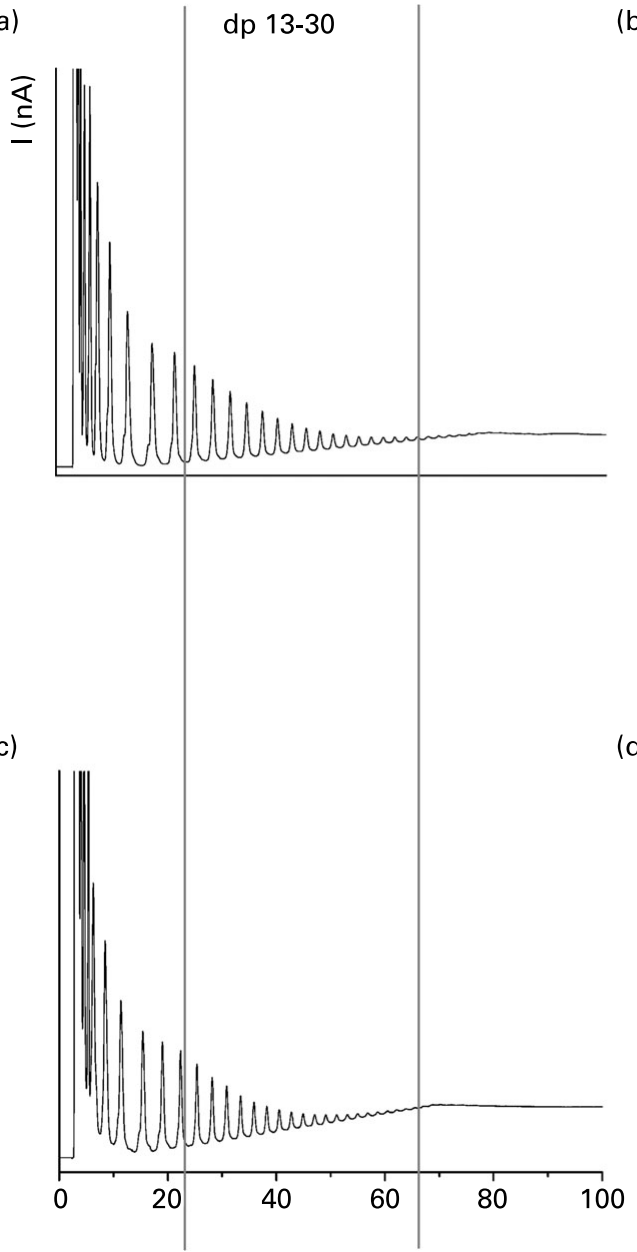

(b)

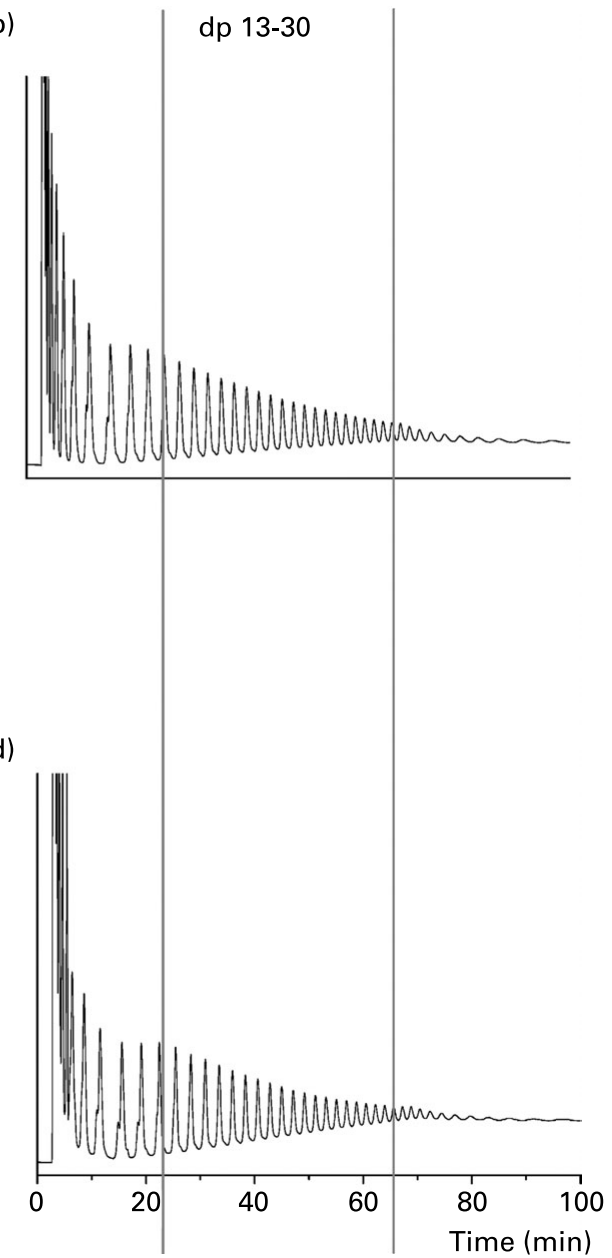

Fig. 1. High-performance anion-exchange chromatography with pulsed amperometric detection of (a) chicory inulin (CH); (b) Jerusalem artichoke inulin (JA); (c) snack bar with $\mathrm{CH}$; (d) snack bar with JA. dp, degree of polymerization; I, amperage.

determined with the method used for $\mathrm{CH}$ and JA, are comparable. We found an amount of $20.8 \mathrm{~g}$ inulin (JA) or $21.0 \mathrm{~g}$ inulin $(\mathrm{CH})$, respectively, per $100 \mathrm{~g}$ of the snack bar. Relating to a snack bar with a weight of $36 \mathrm{~g}$, this corresponds to an amount of $7.5 \mathrm{~g}$ inulin per bar and is in good agreement with the expected amount $(7.7 \mathrm{~g} \mathrm{CH} / \mathrm{JA})$. No inulin was found in the placebo snack bar.

\section{Faecal microflora}

Baseline data of faecal microbial populations at the end of the run-in period showed that no significant differences existed among volunteers due to normal biological fluctuation in the composition of the faecal microflora (Table 1).

After consuming $\mathrm{CH}$ or JA compared with placebo, total bacterial numbers were constant throughout the study, but there were differences with respect to counts and frequency of certain bacterial groups (Table 1). No time effects on the different bacterial counts were observed in the placebo group. In subjects consuming $\mathrm{CH}$ or $\mathrm{JA}$, a steady increase in bifidobacteria by approximately $1.2 \log$ in 3 weeks was observed and there were significant differences in bifidobacterial numbers compared to the placebo group at all sampling times of the intervention period $(P<0.05)$.

On the final sampling day (intervention, day 28), in contrast, subjects consuming $\mathrm{CH}$ or JA showed lower numbers of Bacteroides/Prevotella than the placebo group $(P<0.05)$. At the same time, potential pathogenic bacteria of the Clostridium histolyticum and $C$. lituseburense group were less frequently isolated $(P<0.05)$ in JA or were beyond the detection limit in $\mathrm{CH}$ subjects.

Compared to the placebo group, subjects who had consumed $\mathrm{CH}$ or JA showed approximately $0.6 \mathrm{log}$ less numbers of the Clostridium coccoides/Eubacterium rectale group at the end of the intervention period (day 28) than at the end of the run-in phase (day 7). Counts of Enterobacteriacea were higher in subjects consuming $\mathrm{CH}$ than in those consuming JA only at the end of the first week of intervention (day 14). No differences among groups were noted in counts and frequency of Faecalibacterium prausnitzii, the Atopobium group, Lactobacillus, Enterococcus, C. perfringens and yeasts (Table 1).

Overall, the chosen method allowed us to assign up to $62 \%$ of the total bacteria detected with the mixture of five bacteriadirected probes to distinct bacterial groups. 
Table 1. Faecal bacteria $\left(\log _{10}\right.$ counts/g wet weight) in faeces of healthy volunteers before and after consuming snack bars containing chicory inulin $(\mathrm{CH})$ or Jerusalem artichoke inulin $(\mathrm{JA})$ v. placebo

\begin{tabular}{|c|c|c|c|c|c|c|c|c|c|}
\hline & \multicolumn{3}{|c|}{ Placebo ( $n$ 15) } & \multicolumn{3}{|c|}{$\mathrm{CH}(n 15)$} & \multicolumn{3}{|c|}{$\mathrm{JA}(n 15)$} \\
\hline & Mean & $\%$ & SD & Mean & $\%$ & SD & Mean & $\%$ & SD \\
\hline \multicolumn{10}{|c|}{ Total bacteriał } \\
\hline \multicolumn{10}{|c|}{ Run-in (end) } \\
\hline Day 7 & $10 \cdot 6$ & & 0.2 & $10 \cdot 6$ & & 0.2 & $10 \cdot 7$ & & 0.2 \\
\hline \multicolumn{10}{|c|}{ Intervention } \\
\hline Day 14 & 10.5 & & 0.2 & $10 \cdot 7$ & & 0.1 & $10 \cdot 8$ & & 0.2 \\
\hline Day 21 & $10 \cdot 6$ & & 0.1 & $10 \cdot 6$ & & 0.2 & $10 \cdot 7$ & & 0.2 \\
\hline Day 28 & $10 \cdot 6$ & & 0.1 & $10 \cdot 7$ & & 0.1 & $10 \cdot 7$ & & 0.2 \\
\hline \multicolumn{10}{|c|}{ Clostridium coccoides/Eubacterium rectale cluster $\ddagger$} \\
\hline \multicolumn{10}{|c|}{ Run-in (end) } \\
\hline Day 7 & $9 \cdot 8$ & & 0.2 & $9 \cdot 9$ & & 0.4 & $9 \cdot 8$ & & 0.3 \\
\hline \multicolumn{10}{|c|}{ Intervention } \\
\hline Day 14 & $9 \cdot 7$ & & 0.3 & 9.9 & & 0.1 & $9 \cdot 7$ & & 0.2 \\
\hline Day 21 & $9 \cdot 6$ & & 0.3 & $9 \cdot 7$ & & 0.1 & $9 \cdot 7$ & & 0.2 \\
\hline Day 28 & 9.5 & & 0.4 & $9.3^{*}$ & & 0.3 & $9 \cdot 2^{*}$ & & 0.5 \\
\hline \multicolumn{10}{|c|}{ Bacteroides/Prevotellał } \\
\hline Run-in (en & & & & & & & & & \\
\hline Day 7 & $10 \cdot 2$ & & 0.2 & $10 \cdot 3$ & & 0.3 & $10 \cdot 4$ & & 0.2 \\
\hline Interventio & & & & & & & & & \\
\hline Day 14 & $10 \cdot 2$ & & 0.2 & $10 \cdot 1$ & & 0.2 & $10 \cdot 2$ & & 0.4 \\
\hline Day 21 & $10 \cdot 2$ & & 0.2 & $10 \cdot 1$ & & 0.3 & $10 \cdot 1$ & & 0.5 \\
\hline Day 28 & $10 \cdot 3^{a}$ & & 0.2 & $9.9^{b *}$ & & 0.3 & $9 \cdot 8^{\mathrm{b} *}$ & & 0.4 \\
\hline Faecalibacte & rausnitz & & & & & & & & \\
\hline Run-in (en & & & & & & & & & \\
\hline Day 7 & $8 \cdot 1$ & & 0.4 & $8 \cdot 3$ & & 0.5 & $8 \cdot 3$ & & 0.4 \\
\hline Interventio & & & & & & & & & \\
\hline Day 14 & $8 \cdot 1$ & & 0.4 & $8 \cdot 2$ & & 0.3 & $8 \cdot 3$ & & 0.2 \\
\hline Day 21 & $8 \cdot 1$ & & 0.5 & 8.0 & & 0.4 & $8 \cdot 2$ & & 0.3 \\
\hline Day 28 & 8.0 & & 0.5 & $8 \cdot 1$ & & 0.5 & $8 \cdot 1$ & & 0.5 \\
\hline Bifidobacteri & & & & & & & & & \\
\hline Run-in (en & & & & & & & & & \\
\hline Day 7 & $8 \cdot 3$ & & 0.6 & 8.4 & & 0.4 & 8.5 & & 0.5 \\
\hline Interventio & & & & & & & & & \\
\hline Day 14 & $8 \cdot 5^{a}$ & & 0.5 & $8.9^{b_{*}}$ & & 0.3 & $9 \cdot 2^{\mathrm{b} *}$ & & 0.4 \\
\hline Day 21 & $8 \cdot 6^{\mathrm{a}}$ & & 0.5 & $9 \cdot 2^{b *}$ & & 0.4 & $9 \cdot 4^{b *}$ & & 0.4 \\
\hline Day 28 & $8 \cdot 6^{a}$ & & 0.5 & $9 \cdot 6^{\mathrm{b} *}$ & & 0.4 & $9 \cdot 7^{\mathrm{b} *}$ & & 0.5 \\
\hline Atopobium $\mathrm{g}$ & & & & & & & & & \\
\hline Run-in (en & & & & & & & & & \\
\hline Day 7 & 8.9 & & 0.4 & $9 \cdot 1$ & & 0.3 & $9 \cdot 1$ & & 0.3 \\
\hline Interventio & & & & & & & & & \\
\hline Day 14 & 8.9 & & 0.3 & 9.0 & & 0.3 & $9 \cdot 1$ & & 0.3 \\
\hline Day 21 & 8.9 & & 0.3 & $9 \cdot 2$ & & 0.3 & $9 \cdot 1$ & & 0.4 \\
\hline Day 28 & 8.9 & & 0.5 & 9.1 & & 0.4 & 8.9 & & 0.6 \\
\hline Lactobacillus & & & & & & & & & \\
\hline Run-in (en & & & & & & & & & \\
\hline Day 7 & $6 \cdot 8$ & & $1 \cdot 1$ & $6 \cdot 7$ & & 1.6 & $6 \cdot 6$ & & 1.2 \\
\hline Interventio & & & & & & & & & \\
\hline Day 14 & 6.5 & & 1.2 & $6 \cdot 0$ & & 1.2 & $6 \cdot 1$ & & $1 \cdot 1$ \\
\hline Day 21 & $6 \cdot 2$ & & 1.3 & $6 \cdot 1$ & & 0.7 & 5.9 & & 1.4 \\
\hline Day 28 & $6 \cdot 1$ & & 1.4 & $5 \cdot 8$ & & 1.2 & $6 \cdot 1$ & & 1.5 \\
\hline Enterococcu & & & & & & & & & \\
\hline Run-in (en & & & & & & & & & \\
\hline Day 7 & $5 \cdot 0$ & & 1.6 & $5 \cdot 2$ & & 1.8 & 4.8 & & 1.5 \\
\hline Interventio & & & & & & & & & \\
\hline Day 14 & 4.9 & & $2 \cdot 1$ & 4.7 & & 1.6 & $4 \cdot 8$ & & 1.8 \\
\hline Day 21 & 4.3 & & 1.2 & 4.4 & & 1.6 & 4.4 & & 1.2 \\
\hline Day 28 & $5 \cdot 4$ & & $1 . \overline{6}$ & 4.3 & & $1 \cdot 1$ & 4.4 & & 1.4 \\
\hline Enterobacte & & & & & & & & & \\
\hline Run-in (en & & & & & & & & & \\
\hline Day 7 & $6 \cdot 5$ & & 0.9 & $6 \cdot 3$ & & 1.5 & 5.9 & & 1.6 \\
\hline Interventio & & & & & & & & & \\
\hline Day 14 & $6 \cdot 6$ & & 0.9 & $7 \cdot 0$ & & 0.8 & $5 \cdot 8$ & & 1.4 \\
\hline Day 21 & $6 \cdot 4$ & & 1.3 & $6 \cdot 3$ & & 0.8 & $5 \cdot 6$ & & $1 \cdot 8$ \\
\hline Day 28 & $5 \cdot 8$ & & 1.2 & 5.9 & & $1 \cdot 1$ & $5 \cdot 0$ & & 1.5 \\
\hline Clostridium I & icum grc & and & lituse & ense gr & & & & & \\
\hline Run-in (en & & & & & & & & & \\
\hline Day 7 & $5 \cdot 6$ & & 0.3 & 5.5 & & 0.3 & 5.4 & & 0.3 \\
\hline
\end{tabular}


Table 1. Continued

\begin{tabular}{|c|c|c|c|c|c|c|c|c|c|}
\hline & \multicolumn{3}{|c|}{ Placebo ( $n$ 15) } & \multicolumn{3}{|c|}{$\mathrm{CH}(n 15)$} & \multicolumn{3}{|c|}{$\mathrm{JA}(n$ 15) } \\
\hline & Mean & $\%$ & SD & Mean & $\%$ & SD & Mean & $\%$ & SD \\
\hline \multicolumn{3}{|l|}{ Intervention } & & 10 & 67 & & 10 & 67 & \\
\hline Day 14 & $5 \cdot 6$ & & 0.3 & $5 \cdot 4$ & & 0.3 & $5 \cdot 4$ & & 0.3 \\
\hline Occurrence & 12 & 80 & & 7 & 47 & & 9 & 60 & \\
\hline Day 21 & 5.5 & & 0.3 & $5 \cdot 2$ & & 0.2 & $5 \cdot 4$ & & 0.2 \\
\hline Occurrence & 12 & 80 & & $6 \dagger$ & 40 & & $6 \dagger$ & 40 & \\
\hline Day 28 & $5 \cdot 6$ & & 0.3 & ND & & & $5 \cdot 3$ & & 0.2 \\
\hline \multirow{2}{*}{\multicolumn{10}{|c|}{ C. perfringens§ }} \\
\hline & & & & & & & & & \\
\hline \multicolumn{10}{|l|}{ Run-in (end) } \\
\hline Day 7 & $4 \cdot 1$ & & 0.5 & 3.9 & & 1.3 & 4.0 & & 0.9 \\
\hline Occurrence & 8 & 53 & & 5 & 33 & & 10 & 67 & \\
\hline \multicolumn{10}{|l|}{ Intervention } \\
\hline Day 14 & 3.9 & & $1 \cdot 1$ & 3.9 & & 0.6 & 3.9 & & 0.2 \\
\hline Occurrence & 6 & 40 & & 7 & 47 & & 3 & 20 & \\
\hline Day 21 & 4.4 & & 1.1 & 4.0 & & $1 \cdot 0$ & 3.5 & & 0.3 \\
\hline Occurrence & 7 & 47 & & 5 & 33 & & 4 & 27 & \\
\hline Day 28 & 4.2 & & 0.7 & $4 \cdot 3$ & & 0.6 & 3.9 & & 0.7 \\
\hline Occurrence & 7 & 47 & & 2 & 13 & & 4 & 27 & \\
\hline \multicolumn{10}{|l|}{ Yeasts§ } \\
\hline \multicolumn{10}{|l|}{ Run-in (end) } \\
\hline Day 7 & $4 \cdot 0$ & & 0.8 & $3 \cdot 7$ & & 0.6 & 3.6 & & 0.7 \\
\hline Occurrence & 9 & 60 & & 10 & 67 & & 10 & 67 & \\
\hline \multicolumn{10}{|l|}{ Intervention } \\
\hline Day 14 & 3.7 & & 0.7 & 3.9 & & 0.9 & $3 \cdot 8$ & & 0.5 \\
\hline Occurrence & 9 & 60 & & 11 & 73 & & 9 & 60 & \\
\hline Day 21 & 3.5 & & 0.5 & 3.7 & & 0.7 & 3.5 & & 0.5 \\
\hline Occurrence & 6 & 40 & & 11 & 73 & & 9 & 60 & \\
\hline Day 28 & 3.6 & & 0.7 & 3.6 & & 0.6 & $3 \cdot 8$ & & 0.6 \\
\hline Occurrence & 3 & 20 & & 7 & 47 & & 7 & 47 & \\
\hline \multicolumn{10}{|c|}{$\begin{array}{l}N D \text {, not detected. } \\
a, b \text { Mean values within a row with unlike superscript letters were significantly different }(P<0.05)\end{array}$} \\
\hline \multicolumn{10}{|c|}{$\begin{array}{l}\text { Mean values were significantly different from those of the run-in period: }{ }^{*} P<0.05 \text {. } \\
\text { Mean values were significantly different from those of the placebo group: } \dagger P<0.05 \text {. } \\
\text { ‡Bacterial counts were assessed by fluorescent in situ hybridization. } \\
\text { §Bacterial counts (colony forming units) were assessed by conventional culture methods. } \\
\text { | The occurrence of organisms is expressed as the number of subjects colonized with percentage. Microbia } \\
\text { groups without given occurrence were detected in all subjects per group }(n 15 ; 100 \%) \text {. }\end{array}$} \\
\hline
\end{tabular}

\section{SCFA}

Parallel to microbiological studies faecal samples were analysed for SCFA. Faecal concentrations of total SCFA ( $\mu \mathrm{mol} / \mathrm{g}$ wet weight) did not differ significantly between treatment groups: for example 138.8 (SD 39.4) in the placebo group, 142.4 (SD 43.7) in the CH group and 135.2 (SD 50.7) in the JA group at the end of the intervention period. The same also applied to faecal concentrations of the individual SCFA, i.e. acetic, propionic, $n$-butyric and of the sum of iso- $\mathrm{C}_{4}-\mathrm{C}_{6}$ fatty acids (data not shown). The molar proportion of acetic, propionic, $n$-butyric and of the sum of iso- $\mathrm{C}_{4}-\mathrm{C}_{6}$ fatty acids varied from 64 to $70 \%, 14$ to $16 \%, 11$ to $13 \%$ and 4 to $6 \%$, respectively, for all treatments at the end of the intervention period $(P>0.05)$.

\section{Bowel habit and gastrointestinal symptoms}

Consumption of snack bars resulted in a slight increase in stool frequency to approximately nine or ten bowel movements per week, independent of $\mathrm{CH}$, JA or placebo consumption (Table 2). Stool consistency, however, was only slightly affected in subjects consuming two snack bars with $\mathrm{CH}$ or JA per day in the second and/or third week of intervention
$(P<0.05)$. The main reported daily stool forms were rated between cylindrical formed to soft (Table 2).

Gastrointestinal complaints concerning flatulence were significant higher $(P<0.05)$ during consumption of $\mathrm{CH}$ or JA compared with placebo (Table 3). This intestinal characteristic, however, was usually mild and sometimes moderate and in no case led to discontinuation of the study (Table 4). The other subjective gastrointestinal parameters were not significantly affected by treatment (Table 3), although few subjects rarely reported mild discomfort after consuming $\mathrm{CH}$ or JA.

\section{Discussion}

The increasing consumer awareness that diet and health are linked is stimulating the development of novel products by the food industry. However, little information exists on how food processing, such as thermal treatment of the raw materials of inulin-type fructans in bakery products, may affect their prebiotic properties in vivo. Moreover, only a few studies have addressed the effects of the chemistry and structure of fructans on the composition and the microbial 
Table 2. Stool frequency and stool consistency of healthy volunteers before and after consuming snack bars containing chicory inulin ( $\mathrm{CH}$ ) or Jerusalem artichoke inulin (JA) v. placebo

\begin{tabular}{|c|c|c|c|c|c|c|}
\hline & \multicolumn{2}{|r|}{ Placebo (n 15) } & \multicolumn{2}{|r|}{$\mathrm{CH}(n 15)$} & \multicolumn{2}{|r|}{$\mathrm{JA}(n 15)$} \\
\hline & Median & Lower and upper quartiles & Median & Lower and upper quartiles & Median & Lower and upper quartiles \\
\hline \multicolumn{7}{|l|}{ Stool frequency $\ddagger$} \\
\hline \multicolumn{7}{|l|}{ Run-in } \\
\hline Days $1-7$ & $7^{a}$ & 7,9 & $7^{a}$ & 6,10 & $7^{a}$ & 7,9 \\
\hline \multicolumn{7}{|l|}{ Intervention } \\
\hline Days 8-14 & $8^{a}$ & 7,9 & $9^{a}$ & 6,12 & $8^{b}$ & 7,10 \\
\hline Days $15-21$ & $9^{b}$ & 8,10 & $10^{\mathrm{b}}$ & 7,12 & $9^{c}$ & 7,13 \\
\hline Days $22-28$ & $9^{b}$ & 7,13 & $10^{b}$ & 7,15 & $9^{\mathrm{b}, \mathrm{c}}$ & 7,11 \\
\hline \multicolumn{7}{|l|}{ Stool consistency§ } \\
\hline \multicolumn{7}{|l|}{ Run-in } \\
\hline Days $1-7$ & $13^{a}$ & 11,14 & $12^{\mathrm{a}}$ & 10,14 & $12^{\mathrm{a}}$ & 10,14 \\
\hline \multicolumn{7}{|l|}{ Intervention } \\
\hline Days 8-14 & $13^{a}$ & 12,14 & $12^{a}$ & 10,13 & $14^{\mathrm{a}}$ & 12,15 \\
\hline Days $15-21$ & $14^{\mathrm{a}}$ & 14,14 & $14^{b}$ & 12,14 & $14^{\mathrm{a}}$ & 11,15 \\
\hline Days $22-28$ & $14^{a}$ & 14,14 & $14^{b}$ & 13,17 & $15^{b}$ & 13,16 \\
\hline
\end{tabular}

${ }_{a, b, c}$ Median values within a column with unlike superscript letters were significantly different $(P<0.05)$.

$\ddagger$ Stool frequency expressed as number of stools per $7 \mathrm{~d}$.

$\S$ Stool consistency expressed as sum of scores per $7 \mathrm{~d}$. Daily scores: 1 , hard pellets; 2 , cylindric formed; 3 , soft, pudding-like; 4 , watery.

activity of the gastrointestinal microflora during its continued administration.

The results of the present study show that $\mathrm{CH}$ and JA in bakery products, namely in our snack bars, resulted in marked changes in faecal microbiota measured by conventional culture techniques and fluorescent in situ hybridization with 16S/23S rRNA-targeted oligonucleotide probes. To our knowledge, this was the first study investigating prebiotic properties of the above fructans after bakery processing in vivo in a 3-week double-blinded placebo-controlled intervention trial.

It is noteworthy that both $\mathrm{CH}$ and JA had similar structures before and after processing of the snack bars. HPAEC-PAD analysis indicates that the samples used $(\mathrm{CH}, \mathrm{JA})$ had similar inulin profiles (Fig. 1(a, b)). The HPAEC-PAD patterns obtained after separation of extracts from inulin-containing snack bars (Fig. 1(c, d)) showed no explicit differences compared to the inulin profiles of the raw materials $\mathrm{CH}$ and JA (Fig. 1(a, b)). Thus, the production process does not lead to a change of the inulin profile and the content of inulin. This is probably due to the fact that during the production process the snack bars are heated at relatively low temperatures. Dry heating of inulin from chicory for up to $60 \mathrm{~min}$ at temperatures between 135 and $195^{\circ} \mathrm{C}$ resulted in a significant degradation of the fructan ranging from 20 to $100 \%{ }^{12}$. In vitro fermentation experiments with highly heated inulin from Jerusalem artichoke showed an improved prebiotic effect for the heated samples compared to the unheated samples ${ }^{26}$. We suppose that di-D-fructose dianhydrides found during heating from fructo-oligosaccharides may be responsible for this phenomenon, as di-d-fructose dianhydrides were found to be prebiotic in former studies ${ }^{27,28}$. This hypothesis, however, must be proven in further studies. Thus, baking products containing higher-heated inulin should be investigated regarding the degradation products of inulin and their prebiotic effects.

In view of the finding that $\mathrm{CH}$ and JA did not differ in structure after bakery processing we expected similar effects of these fructans on the intestinal microbiota of healthy human subjects consuming snack bars containing $\mathrm{CH}$ or JA. One important finding of the present study concerns the increase in faecal bifidobacteria in volunteers consuming $\mathrm{CH}$ or JA compared with placebo. Such observation is well in line with the hypothesis that the prebiotic acts as a selective substrate on which the bifidobacteria grow ${ }^{1}$. In the present study the increase in bifidobacteria was detected after only 1 week of consumption of one snack bar providing the lower dose of approximately $7.7 \mathrm{~g}$ fructan/d. The present observation is consistent with previous microbiological results obtained by

Table 3. Subjects reporting gastrointestinal complaints after consuming snack bars containing chicory inulin $(\mathrm{CH})$ or Jerusalem artichoke inulin (JA) v. placebo

\begin{tabular}{|c|c|c|c|c|c|c|}
\hline \multirow[b]{2}{*}{ Symptoms } & \multicolumn{2}{|c|}{$\begin{array}{c}\text { Placebo } \\
(n 15)\end{array}$} & \multicolumn{2}{|c|}{$\mathrm{CH}(n 15)$} & \multicolumn{2}{|c|}{$\mathrm{JA}(n 15)$} \\
\hline & $n$ & $\%$ & $n$ & $\%$ & $n$ & $\%$ \\
\hline \multicolumn{7}{|l|}{ Flatulence } \\
\hline Days $8-14$ & $7^{a}$ & 47 & $12^{\mathrm{b}}$ & 80 & $14^{\mathrm{b}}$ & 93 \\
\hline Days $15-21$ & $6^{a}$ & 40 & $13^{b}$ & 87 & $14^{b}$ & 93 \\
\hline Days $22-28$ & $7^{a}$ & 47 & $13^{b}$ & 87 & $14^{b}$ & 93 \\
\hline \multicolumn{7}{|c|}{ Abdominal bloating } \\
\hline Days $8-14$ & 3 & 20 & 4 & 27 & 4 & 27 \\
\hline Days $15-21$ & 4 & 27 & 3 & 20 & 3 & 20 \\
\hline Days 22-28 & 4 & 27 & 0 & 0 & 4 & 27 \\
\hline \multicolumn{7}{|c|}{ Abdominal pain or cramps } \\
\hline Days 8-14 & 1 & 7 & 0 & 0 & 1 & 7 \\
\hline Days $15-21$ & 2 & 13 & 2 & 13 & 4 & 27 \\
\hline Days 22-28 & 1 & 7 & 3 & 20 & 1 & 7 \\
\hline \multicolumn{7}{|l|}{ Bowel rumbling } \\
\hline Days 8-14 & 2 & 13 & 2 & 13 & 3 & 20 \\
\hline Days $15-21$ & 1 & 7 & 5 & 33 & 1 & 7 \\
\hline Days $22-28$ & 2 & 13 & 2 & 13 & 2 & 13 \\
\hline \multicolumn{7}{|l|}{ Bowel cramps } \\
\hline Days 8-14 & 1 & 7 & 2 & 13 & 4 & 27 \\
\hline Days $15-21$ & 1 & 7 & 4 & 27 & 4 & 27 \\
\hline Days 22-28 & 2 & 13 & 3 & 20 & 3 & 20 \\
\hline
\end{tabular}


Table 4. Severity of the reported symptom 'flatulence' in healthy volunteers before and after consuming snack bars containing chicory inulin ( $\mathrm{CH}$ ) or Jerusalem artichoke inulin (JA) v. placebo

\begin{tabular}{|c|c|c|c|c|c|c|}
\hline & \multicolumn{2}{|r|}{ Placebo (n 15) } & \multicolumn{2}{|r|}{$\mathrm{CH}(n 15)$} & \multicolumn{2}{|r|}{$\mathrm{JA}(n 15)$} \\
\hline & Median & Lower and upper quartiles & Median & Lower and upper quartiles & Median & Lower and upper quartiles \\
\hline \multicolumn{7}{|l|}{ Flatulenceł } \\
\hline \multicolumn{7}{|l|}{ Run-in } \\
\hline Days $1-7$ & 0 & 0,1 & 0 & 0,1 & 0 & 0,2 \\
\hline \multicolumn{7}{|l|}{ Intervention } \\
\hline Days 8-14 & $0^{\mathrm{a}}$ & 0,3 & $3^{\mathrm{b}}$ & 2,7 & $3^{\mathrm{b}}$ & 1,4 \\
\hline Days $15-21$ & $0^{\mathrm{a}}$ & 0,3 & $4^{b}$ & 7,9 & $5^{b}$ & 2,8 \\
\hline Days $22-28$ & $0^{\mathrm{a}}$ & 0,2 & $5^{\mathrm{b}}$ & 2,10 & $4^{\mathrm{b}}$ & 1,7 \\
\hline
\end{tabular}

${ }^{a, b}$ Mean values within a row with unlike superscript letters were significantly different $(P<0.05)$.

‡ 'Flatulence' symptom intensity was expressed as sum of scores per $7 \mathrm{~d}$. Ranking: 0, absent; $1-7$ mild; 8-14 moderate; $15-21$ severe.

other trials in man. Bouhnik et al. ${ }^{9,29}$ have observed that numbers of bifidobacteria in volunteers increased after a $7 \mathrm{~d}$ feeding period of short-chain fructans. $\mathrm{Rao}^{30}$ demonstrated that a low dose of oligofructose $(5 \mathrm{~g} / \mathrm{d})$ resulted in an increase in faecal bifidobacteria by approximately $1.0 \log$ after $11 \mathrm{~d}$. Contrary to other studies, however, which have demonstrated that inulin consumption in the second week or as long as the prebiotic was eaten did not further increase numbers of bifidobacteria $^{10,11}$, the present results support the hypothesis that after an initial adaptation period, a higher dosage of fructans (two snack bars per day providing the dosage of approximately $14.5 \mathrm{~g}$ fructan/d) may lead to increased faecal numbers of bifidobacteria (Table 1). The increase in bifidobacteria in the intestine of the volunteers consuming $\mathrm{CH}$ or JA may contribute to the health of the host. Among the major bacterial groups of colonic bacteria, Bifidobacterium are usually thought to be apathogenic ${ }^{31}$. These organisms may increase resistance to disease by reducing the growth of pathogenic and putrefactive bacteria by lowering $\mathrm{pH}$, competing directly for substrates and/or attachment sites on the epithelial mucus layer, producing inhibitory molecules and stimulating the enteric immune system ${ }^{31-34}$.

It is noteworthy that the increase in bifidobacteria in the present study was paralleled by a decrease of various potential pathogenic bacterial groups, such as Bacteroides/Prevotella in number and the Clostridium histolyticum/C. lituseburense group in frequency. The latter effects reached significance $(P<0.05)$ after the 3 -week intervention period in the faeces (Table 1), suggesting the need for a certain time of adaptation. Other, mainly short-time, nutrition trials using inulin-type fructans often failed to show changes in the composition of the gut microflora towards reducing the number of species which are considered to be harmful to the host ${ }^{8,10,13}$.

It should be noted that several of the fluorescent in situ hybridization probes employed in the present study target quite large and diverse groups of bacteria. Therefore the study does not exclude the possibility that inulin-driven changes might also occur in some components of these groups. Moreover, it cannot be excluded that other known or unknown bacteria, which were not detected with the set of probes used in the present study, may be affected by $\mathrm{CH}$ and/or JA.

In view of the changes in the microbial counts after $\mathrm{CH}$ or JA consumption, we expected alteration in indexes of microbial metabolism such as luminal SCFA. The present results show, however, that the faecal output of SCFA was not significantly affected by either $\mathrm{CH}$ or JA intake. This may be because the concentrations of SCFA in the faeces do not reflect the differences in their rate of production by the colonic flora. Moreover, SCFA concentrations are markedly affected by their distribution volume and their absorption rate (up to $95 \%$ in human intestine) ${ }^{35,36}$. Only a small proportion of all SCFA produced in the large bowel is excreted in the faeces. Therefore, faecal data are of low physiological relevance. For this reason new areas of interest in this field should be the direct effects of SCFA on immune cells and immune function (e.g. cytokine production). Mechanisms of mucosal protection in relation to alteration of levels of SCFA should be addressed.

Several studies in man have shown that fermentation of inulin-type fructans may stimulate bowel movements and may normalize stool frequency, especially in slightly constipated subjects ${ }^{3,7,8}$. In the present study the volunteers were variable in their response to $\mathrm{CH}$ or JA. The data indicate a slight laxative effect of $\mathrm{CH}$ or JA in healthy volunteers (Table 2). In accordance with other studies, indicating efficient fermentation of fructans in the colon ${ }^{14,37,38}$, this positive effect was sometimes accompanied by a slight abdominal discomfort. Mainly flatulence was reported by a few volunteers, who reported mild and sometimes moderate discomfort after consuming $\mathrm{CH}$ or JA (Table 4).

The formation of hydrogen, which is a metabolic end-product of bacterial fermentation in the colon, is most probably the major cause of this symptom. However, it has to be emphasized that bifidobacteria, the numbers of which are increased significantly with inulin, are not considered to be producers of hydrogen. For this reason, the relationship between specific intestinal bacteria and gas production as a result of colonic fermentation remains to be clarified.

It should be mentioned that the present study extends earlier studies conducted in man and human flora-associated rats ${ }^{8,15}$ using a stepwise adaptation on the doses of inulin-type fructans. The strategy of adaptation was effective in producing changes in the microbiota, namely by increasing bifidobacteria, that persisted during the intervention period and resulted in a decrease of potentially harmful bacteria at the end of the intervention. Further studies are needed to clarify whether long-term consumption of $\mathrm{CH}$ or JA may lead to further changes or to stabilization of the altered microbiota and whether alterations in colonic function and microflora may 
be detectable in volunteers after the dietary intervention has ended.

In summary, the data indicate that JA in bakery products resulted in similar effects on microbiota and bowel habit compared with $\mathrm{CH}$, the so-called gold-standard for the demonstration of a prebiotic effect. The prebiotic nature of the raw materials was maintained in the processed snack bars.

\section{Acknowledgements}

We are especially grateful to our volunteers for their cooperation. The expert technical assistance of Gabriele Dobeleit and Gerald Vallentin for SCFA analysis is acknowledged. We thank Dr Quendt GmbH, Dresden, Germany for preparation of the snack bars. This study was partly supported by a BMBF InnoRegio BioMeT-Project.

\section{References}

1. Gibson GR \& Roberfroid MB (1995) Dietary modulation of the human colonic microbiota: introducing the concept of prebiotics. J Nutr 125, 1401-1412.

2. Van Loo J, et al. (1999) Functional food properties of nondigestible oligosaccharides: a consensus report from the ENDO project (DGXII AIRIICT94-1095). Br J Nutr 81, $121-132$.

3. Roberfroid M (1993) Dietary fiber, inulin, and oligofructose: a review comparing their physiological effects. Crit Rev Food Sci Nutr 33, 103-148.

4. Roberfroid M (1995) Introducing inulin-type fructans. Br J Nutr 93, $\mathrm{S} 13-\mathrm{S} 25$.

5. Van Loo, J (2004) Prebiotics promote good health. The basis, the potential and the emerging evidence. J Clin Gastroenterol 38, S70-S75.

6. Gibson GR, Probert HM, Van Loo J, Rastall RA \& Roberfroid M (2005) Dietary modulation of the human colonic microbiota: updating the concept of prebiotics. Nutr Res Rev 17, 259-275.

7. Gibson GR, Beatty ER, Wang X \& Cummings JH (1995) Selective stimulation of bifidobacteria in the human colon by oligofructose and inulin. Gastroenterology 108, 975-982.

8. Kleessen B, Sykura B, Zunft H-J \& Blaut M (1997) Effects of inulin and lactose on fecal microflora, microbial activity, and bowel habit in elderly constipated persons. Am J Clin Nutr 65, 1397-1402.

9. Bouhnik Y, Vahedi K, Achour L, Attar A, Salfati J, Porchart P, Marteau P, Flourié B, Bornet F \& Rambaud J-C (1999) Shortchain fructo-oligosaccharide administration dose-dependently increases fecal bifidobacteria in healthy humans. J Nutr 129, $113-116$.

10. Menne E, Guggenbuhl N \& Roberfroid M (2000) Fn-type chicory inulin hydrolysate has a prebiotic effect in humans. J Nutr 130, 1197-1199.

11. Tuohy KM, Finlay RK, Wynne AG \& Gibson GR (2001) A human volunteer study on the prebiotic effects of HP inulin - faecal bacteria enumerated using fluorescent in situ hybridization (FISH). Anaerobe 7, 113-118.

12. Boehm A, Kaiser I, Trebstein A \& Henle T (2005) Heat-induced degradation of inulin. Eur Food Res Technol 220, 466-471.

13. Tuohy KM, Kolida S, Lustenberger AM \& Gibson GR (2001) The prebiotic effects of biscuits containing partially hydrolysed guar gum and fructooligosaccharides - a human volunteer study. Br J Nutr 86, 341-348.
14. Kruse H-P, Kleessen B \& Blaut M (1999) Effects of inulin on faecal bifidobacteria in human subjects. Br J Nutr 82, 375-382.

15. Kleessen B, Hartmann L \& Blaut M (2001) Oligofructose and long-chain inulin: influence on the gut microbial ecology of rats associated with a human faecal flora. $\mathrm{Br} J$ Nutr 86, 291-300.

16. Amann RI, Ludwig W \& Schleifer K-H (1995) Phylogenetic identification and in situ detection of individual microbial cells without cultivation. Microbial Rev 59, 143-169.

17. Kleessen B, Noack J \& Blaut M (1999) Distribution of viable and non-viable bacteria in the gastrointestinal tract of gnotobiotic and conventional rats. Microb Ecol Health Dis 11, $218-225$.

18. Franks AH, Harmsen HJM, Raangs GC, Jansen GJ, Shut F \& Welling GW (1998) Variations of bacterial populations in human feces measured by fluorescent in situ hybridization with group-specific 16S rRNA-targeted oligonucleotide probes. Appl Environ Microbiol 64, 3336-3345.

19. Manz W, Amann R, Ludwig W, Vancanneyt M \& Schleifer K$\mathrm{H}$ (1996) Application of a suite of $16 \mathrm{~S}$ rRNA-specific oligonucleotide probes designed to investigate bacteria of the phylum cytophaga-flavobacter-bacteroides in the natural environment. Microbiology 142, 1097-1106.

20. Suau A, Rochet V, Sghir A, Gramet G, Brewayes S, Sutren M, Rigottier-Gois L \& Dore J (2001) Fusobacterium prausnitzii and related species represent a dominant group within the human faecal flora. Syst Appl Microbiol 24, 139-145.

21. Langendijk PS, Schut F, Jansen GJ, Raangs GC, Kamphuis GR, Wilkinson MHF \& Welling GW (1995) Quantitative fluorescence in situ hybridization of Bifidobacterium spp. with genus-specific $16 \mathrm{~S}$ rRNA-targeted probes and its application in fecal samples. Appl Environ Microbiol 61, 3069-3075.

22. Harmsen HJM, Wildeboer-Veloo AC, Grijpstra J, Knol J, Degener JE \& Welling GW (2000) Development of $16 \mathrm{~S}$ rRNA-based probes for the Coriobacterium group and the Atopobium cluster and their application for enumeration of Coriobacteriaceae in human feces from volunteers of different age groups. Appl Environ Microbiol 66, 4523-4527.

23. Kleessen B, Bunke H, Tovar K, Noack J \& Sawatzki K (1995) Influence of two infant formulas and human milk on the development of the faecal flora in newborn infants. Acta Paediatr 84, $1347-1356$.

24. Kleessen B, Elsayed NA, Loehren U, Schroedl W \& Krueger M (2003) Jerusalem artichokes stimulate growth of broiler chickens and protect them against endotoxins and potential cecal pathogens. J Food Prot 66, 2171-2175.

25. Wilcoxon F \& Wilcox RA (1964) Some Rapid Approximate Statistical Procedures. New York: Lederle Laboratories.

26. Boehm A, Kleessen B \& Henle T (2006) Effect of dry heated inulin on selected intestinal bacteria. Eur Food Res Technol 222, 737-740.

27. Orban JI, Patterson JA, Sutton AL \& Richards GN (1997) Effect of sucrose thermal oligosaccharide caramel, dietary vitamin-mineral level and brooding temperature on growth and intestinal bacterial populations of broiler chickens. Poult Sci 76, 482-490.

28. Minamida K, Shiga K, Sujaya IN, Sone T, Yokota A, Hara H, Asano K \& Tomita F (2005) Effects of Difructose Anhydride III (DFA III) administration on rat intestinal microbiota. J Biosci Bioeng 99, 230-236.

29. Bouhnik Y, Raskine L, Simoneau G, Vicaut E, Neut C, Flourié B, Brouns F \& Bornet FR (2004) The capacity of nondigestible carbohydrates to stimulate fecal bifidobacteria in healthy humans: a double-blind, randomized, placebo-controlled, parallel-group, dose-response relation study. Am J Clin Nutr 80, $1658-1664$. 
30. Rao V (2001) The prebiotic properties of oligofructose at low intake levels. Nutr Res 21, 843-848.

31. Tuohy KM, Rouzaud GC, Bruck WM \& Gibson GR (2005) Modulation of the human gut microflora towards improved health using prebiotics - assessment of efficacy. Curr Pharm Des 11, 75-90.

32. Ueda K (1986) Immunity provided by colonized enteric bacteria. Bifido Microflora 5, 67.

33. Gibson GR \& Wang X (1994) Regulatory effects of bifidobacteria on the growth of other colonic bacteria. J Appl Bacteriol 74, 667-674.

34. Picard C, Fioramonti J, Francois A, Robinson T, Neant F \& Matuchansky (2005) Review Article: Bifidobacteria as probiotic agents - physiological effects and clinical benefits. Aliment Pharmacol Ther 22, 495-512.
35. Alles MS, Hautfast JG, Nagengast FM, Hartemink R, Van Laere KM \& Jansen BM (1996) Fate of fructooligosaccharides in the human intestine. $B r J$ Nutr 76, 211-221.

36. Wong JMW, de Souza R, Kendall CWC, Eman A \& Jenkins DJA (2006) Colonic health: fermentation and short chain fatty acids. J Clin Gastroenterol 40, 235-243.

37. Pedersen A, Sandström B \& van Amselvoort JMM (1997) The effect of ingestion of inulin on blood lipids and gastrointestinal symptoms in healthy females. Br $J$ Nutr $\mathbf{7 8}$, 215-222.

38. Sabotka L, Bratowa M, Slemrova M, Manak J, Vizda J \& Zadak $\mathrm{Z}$ (1997) Inulin as the soluble fiber in liquid enteral nutrition. Nutrition 13, 21-25. 